\title{
The Impact of the Pandemic on the Quality of Life of Healthcare Professionals
}

\author{
Lombardo $\mathrm{G}^{1,2 *}$ and Vaccaro $\mathrm{M}^{1,2}$ \\ ${ }^{1}$ Associazione Qui ed Ora, Catanzaro (CZ), Italy \\ ${ }^{2}$ Associazione Un mondo 3d, Beinasco (TO), Italy
}

Research Article

Volume 4 Issue 5

Received Date: September 22, 2020

Published Date: October 14, 2020

DOI: $10.23880 /$ eoij-16000257

*Corresponding author: Lombardo G., Psy. D.; Associazione Qui ed Ora, Italy, Via Redipuglia, 7 Catanzaro, Tel: 3293650511--Email: info@giudittalombardo.it

\section{Abstract}

The state of international public health emergency, declared on January, 30th 2020 has seen an increase in frequency and intensity of health workers in the workplace to support COVID-19 positive patients and indirectly their families. This has seen them come into direct contact with the lives and experiences of other people and with their own, both positive and negative, feeling compassion for those assisted and helplessness in the face of death. The observational study, conducted through the use of Kendall's Self Report questionnaire ProQOL-Professional Quality of Life Scale (2009), version 5, consisting of 30 questions on a Likert scale (from 1 "never" to 5 "very often"), referable to three dimensions: Compassion Fatigue, Burnout and Compassion Satisfaction, allowed the 46 subjects involved to measure their inner resources, assessing the level of stress and emotions experienced. The representative sample of the Calabria region was selected randomly. Everyone was asked to fill in the online questionnaire, after dilling in a descriptive part related to demographic data such as age, sex, marital status, city of residence, profession, city where they work, years of work experience, length of the working week and the impact that the pandemic has had on their work. The results obtained from the research show a reduction in the quality of professional life perceived by health care professionals during the pandemic period.

Keywords: ProQOL; Quality of Life; Healthcare Professionals; COVID-19; Pandemic

\section{Introduction}

Gross and Thomson [1] argue that even before discussing the regulation of emotions is important to understand what the emotion is and then consider it in the context in which it occurs, in order to understand the regulation of emotions from other major forms of self-regulation. The interaction with the surrounding environment requires individuals to continuously regulate their emotions and their expression. The chronic inability to modulate emotional activation can generate numerous psychological problems, relational difficulties and reduced physical well-being. The term "emotional regulation" refers to a series of processes which depend on an individual's goals, which consist of the activation, intensification and/or maintenance of a specific emotion. Regulatory processes can be automatic or controlled, conscious or unconscious; in any case, they involve dynamic changes which last over time [2]. It is important not to neglect the distinction between the modulation of acute emotional states (a state generated by the elicitation of a specific stimulus) and the modulation of durable emotional states. Research has suggested that the adaptive emotional regulation is characterized by the alteration of duration (or intensity) of the emotion rather than the change in the type of emotion experienced. Studies conducted by the Behavioral Sciences say that the emotion affects thinking, decisionmaking, actions, social relations, and well-being, physical and mental health. It is a response to a stimulus and produces physiological changes in heart rate, body temperature and breathe rate [3]. According to Darwin (1872), emotions are innate adaptive responses which are the same in all cultures and independent of learning. Through the execution of innate nervous programs, they produce the configuration of certain facial expressions and body movements; they have both a communicative function (of signalling) and a function of preparing for action; they are also a model of adaptation 
between organism and environment. Emotions are divided into primary emotions (innate and universal) and secondary emotions (which derive from the combination of primary emotions and develop with social interaction); among the primary emotions, we find "anger, fear, sadness, joy, surprise, contempt, disgust"; among the secondary-ones, we find "cheerfulness, envy, anxiety, shame".

Reactions to catastrophic events can cause some of the following symptoms:

- Anxiety: feeling of tension and continuous fear even without an immediate reason;

- Depression: sensation of tiredness and loss of interest;

- Apathy: that is blockage of sensations, often occurs when you become aware of the seriousness of the situation;

- Fear: dread of not making it through the event, or of losing loved ones;

- Sadness: caused by the loss of loved ones or the sight of injured or deceased people:

- Guilt or sense of guilt: it comes from believing that you are in a situation of advantage over others; but it also comes from regret for things not done;

- Shame: you feel reflecting on your own reaction to a situation, i.e. to having seemed vulnerable and unable to deal with it;

- Aggression or irrational anger;

The physical reactions which may occur are no less important: tiredness, insomnia, nightmares, mental fatigue, disorientation, muscle tension. An adaptive regulation includes the modulation of the emotional experience rather than the complete elimination of certain emotions. This means that, in the face of negative and disorganized emotions such as those described above, the modulation of activation facilitates the decline in urgency and trend of action associated with emotion, allowing the individual to control their behaviour in line with the demands of the environment [4,5]. Some conceptualizations have emphasized the functional nature of emotions (positive and negative), suggesting that the lack of ability to experience, differentiate and respond to the full range of emotional experience is as maladaptive as the reduced ability to mitigate and modulate relevant negative emotions [6,7]. The negative effects of experience control efforts and emotional expression based on avoidance are systematically emphasized in the literature. Attempts to avoid internal experiences, such as unwanted thoughts or emotions, can be the cause of various psychological disorders [8]. Avoidance is detrimental to coping strategies [9]. Consequently for the purpose of psychological wellbeing, the conceptualizations of emotional regulation, which emphasize the importance of acceptance and enhancement of emotional responses, assume a central role $[4,6]$. The tendency to feel negative emotions in response to a previous emotional reactions (this indicates a lack of acceptance of the emotional experience itself) is maladaptive and associated with greater difficulty in regulating emotions [10]. The epidemic of severe acute respiratory syndrome SARS-CoV-2 identified with the name COVID-19, originating in Wuhan (China) in December 2019, led the World Health Organization to declare in Italy a state of pandemic since March $11^{\text {th }}, 2020$ which has rapidly affected health care personnel, called to take responsibility and increasing risks $[11,12]$. The context, the mode of intervention, the intensity of the required presence can hinder the well-being of each individual operator and compromise the quality of life [13]. Research conducted by Huggard and colleagues in 2013 [14] defines "components" of Compassion Fatigue, Burnout and secondary traumatic stress. The first involves feeling exhausted and overwhelmed by the situation, as if no action was useful to improve the situation. The second involves feeling the pain of others as if it were your own. Experiencing these feelings for a prolonged period of time leads the individuals to change their vision of reality. Both are frequent sensations in staff providing medical care, with dysfunctional behavioural consequences for the person. It is therefore important to lead the practitioner to recognize the limits of his or her abilities and the consequences that an excess of demands of his or her own and of the work context could have on his or her feelings and behaviour. Compassion Satisfaction refers to the feeling of satisfaction which healthcare professionals feel about the work they do, which can affect the energies involved and their resilience. The observational study conducted aimed to describe the feeling of Compassion Fatigue and Compassion Satisfaction experienced by healthcare workers during the pandemic emergency.

\section{Materials and Methods}

\section{Sample}

The sample is composed of a total of 46 health care professionals $\left(n^{\circ} 8\right.$ psychologists/psychotherapists; $n^{\circ} 4$ pharmacists; $n^{\circ} 21$ doctors; $n^{\circ} 7$ nurses; $n^{\circ} 5$ laboratory health technicians and $n^{\circ} 1$ neuropsychomotricist), all of Italian nationality, domiciled in the Calabria region, chosen randomly. Specifically, women are $84.2 \%$ and men are $15.8 \%$, of which $48.9 \%$ married. Among them, $31.1 \%$ carries out working activity equal to 38 hours, $44.1 \%, 24$ hours and the remaining $24.8 \% 18$ hours.

\section{Materials, Measures and Procedure}

The tool used to assess the quality of psychological wellbeing perceived by social and health care staff is the ProQOL Self Report-Professional Quality of Life Scale by Kendall [15], consisting of 30 questions on a Likert scale (from 1 "never" to 5 "very often"), to which were added ad hoc structured 
questions to obtain the demographic information of the sample, such as age, sex, marital status, city of residence, profession, city wherehe/she works, years of work experience, length of the working week and the impact that the pandemic had on his or her work. The ProQOL questionnaire is the most commonly used test because it measures the negative and positive effects of helping other people who are suffering and experiencing a climate of suffering, change or trauma. In use since 1995, translated into 26 world languages, it presents secondary scales, such as Compassion Satisfaction which concerns the pleasure one feels at having the ability to do one's job. Scores for this item below 0.23 describe that the subjects may have problems with their work. Burnout is one of the elements of Compassion Fatigue, associated with feelings of despair, and difficulty in coping with doing one's work in a capable way. High scores on this scale indicate a higher risk of exhaustion, while below 0.23 shows positive feelings about being effective at work. A score above 0.41 reports a belief in not being effective at work. The second component of Compassion Fatigue is secondary traumatic stress (also known as STS), which refers to work, secondary exposure to extremely or traumatically stressful events. A score above 0.41 describes that the subjects spend a lot of time thinking about stressful events which have arisen and are associated with particular work events (reliability score Alpha scale 0.81) The questionnaire describing the demographic components and the Self-Report ProQOL Professional Quality of Life Scale were both administered in online mode, via drive platform, in a completely random way.

\section{Results}

$17.4 \%$ of the research participants are happy, $30.4 \%$ is sometimes happy, $41.3 \%$ is often happy, $8.7 \%$ is very often happy and $2.2 \%$ never feels happy. As can be seen from figure $1,2.2 \%$ is never concerned about more than one of the people he/she helps, $13 \%$ is rarely concerned about more than one of the people he/she helps, $34.8 \%$ is sometimes concerned about more than one of the people he/she helps and $50 \%$ is often concerned about more than one of the people he/she helps.

I AM CONCERNED ABOUT MORE THAN ONE OF THE PEOPLE I HELP

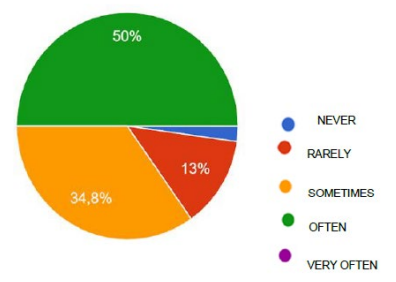

Figure 1: The graph represents the percentage of people interviewed who have experienced feelings of concern about the people they help.
$10.9 \%$ of the sample interviewed doesn't derive satisfaction from being able to help people, $39.1 \%$ sometimes derive satisfaction from being able to help people and 50\% derive satisfaction from being able to help people.

$23.9 \%$ of the subjects sometimes feel in contact with others, $43.5 \%$ often feels in contact with others, $30.4 \%$ very often feels in contact with others, $2.2 \%$ rarely feels in contact with others. $13 \%$ of the sample never bump or startle because of unforeseen noises, $41.3 \%$ of the subjects rarely bump or startle because of unforeseen noises, $30.4 \%$ sometimes bump or startle because of unforeseen noises, $8.7 \%$ often bump or startle because of unforeseen noises and $6.5 \%$ very often bump or startle because of unforeseen noises.

Rarely $8.7 \%$ of respondents reports having more energy after working with those who helps, 32.6\% sometimes has more energy after working with those who helps, 54.3\% often has more energy after working with those who helps and $4.4 \%$ very often has more energy after working with those who helps.

As shown in Figure 2, 26.1\% of the sample never finds it difficult to separate his or her private life from his or her life in the role he or she holds, $19.6 \%$ rarely finds it difficult to separate his or her private life from his or her life in the role he or she holds, $26.1 \%$ sometimes finds it difficult to separate his or her private life from his or her life in the role he or she holds, $23.9 \%$ often finds it difficult to separate his or her private life from his or her life in the role he or she holds, and $4.3 \%$ very often finds it difficult to separate his or her private life from his or her life in the role he or she holds.

I FIND IT DIFFICULT TO SEPARATE MY PRIVATE LIFE FROM THE ROLE I HOLD

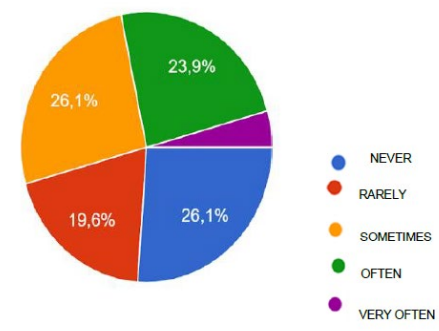

Figure 2: The graph represents the percentage of people interviewed who have experienced difficulties in separating their private life from the role of helper.

$43.5 \%$ is never less productive at work because it is losing sleep because of the traumatic experiences lived by a person who is helping, $28.3 \%$ is rarely less productive at work because it is losing sleep because of the traumatic experiences lived by a person who is helping, $19.6 \%$ is 
sometimes less productive at work because it is losing sleep because of the traumatic experiences lived by a person who is helping and $8.7 \%$ is often less productive at work because it is losing sleep because of the traumatic experiences lived by a person who is helping.

$34.8 \%$ never think he or she has been influenced by the traumatic experiences of the people he or she helps, 34.4\% rarely think he or she has been influenced by the traumatic experiences of the people he or she helps, $26.1 \%$ sometimes think he or she has been influenced by the traumatic experiences of the people he or she helps and $8.7 \%$ think he or she has often been influenced by the traumatic experiences of the people he or she helps.

47.8\% never feel trapped in his or her work as a helper, $23.9 \%$ rarely feel trapped in his or her work as a helper and $19.6 \%$ sometimes feel trapped in his or her work as a helper. According to $45.7 \%$ of respondents, his or her work has never made him or her feel on the edge of the abyss, $28.3 \%$ rarely, $15.2 \%$ sometimes, $7 \%$ often and $2.1 \%$ very often. $6.5 \%$ of the sample likes his or her job as a professional offering help, $34.8 \%$ often likes his or her job as a professional offering help and $58.7 \%$ very often likes his or her job as a professional offering help. $52.2 \%$ never feels depressed because of the traumatic experiences of the people he or she helps, $26.1 \%$ rarely and $17.4 \%$ sometimes feels depressed because of the traumatic experiences of the people he or she helps.

$40 \%$ of subjects never feel as if he or she is experiencing the trauma of one of the people he or she helps, $26.7 \%$ rarely, $28-9 \%$ sometimes and $4.4 \%$ very often. $10.9 \%$ of subjects is sometimes supported by his or her beliefs in his or her work, $58.7 \%$ is often supported by his or her beliefs in his or her work and $30.4 \%$ is very often supported by his or her beliefs in his or her work.

$28.9 \%$ of the subjects are sometimes satisfied with how he or she manages to keep up with the techniques and procedures of assistance and help to others, $51.1 \%$ often, $17.8 \%$ very often and $2.2 \%$ rarely is satisfied with how he or she manages to keep up with the techniques and procedures of assistance and help to others.

$30.4 \%$ is sometimes the person who has always wanted to be, $50 \%$ often, $15.2 \%$ very often, while $4.4 \%$ rarely.

$19.6 \%$ sometimes is satisfied with his or her work, $45.7 \%$ often, $32.6 \%$ very often is satisfied with his or her work and $2.1 \%$ rarely.

As shown in figure 3, 32.6\% of the sample never feels worn out because of his or her role as helper, $30.2 \%$ rarely feels worn out because of his or her role as helper, $25.6 \%$ sometimes feels worn out because of his or her role as helper, $9.3 \%$ often feels worn out because of his or her role as helper and $2.3 \%$ very often feels worn out because of his or her role as helper.

I FEEL WORN OUT BECAUSE OF MY ROLE OF HELPER

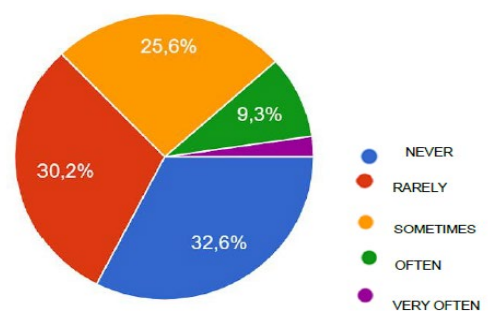

Figure 3: The graph represents the percentage of people interviewed who have experienced a feeling of wear and tear in performing their role.

$17.8 \%$ of health care professionals interviewed very often have positive thoughts and feelings about those he or she helps and how he or she can help, $66.7 \%$ often, 15.6 sometimes.

$24.4 \%$ never feels overwhelmed because his or her workload seems endless.

Figure 4 shows how $6.7 \%$ of the sample rarely believes he or she can make a difference through his or her work, while $13.3 \%$ sometimes.

$60 \%$ often believe he or she can make a difference through his or her work and $20 \%$ very often.

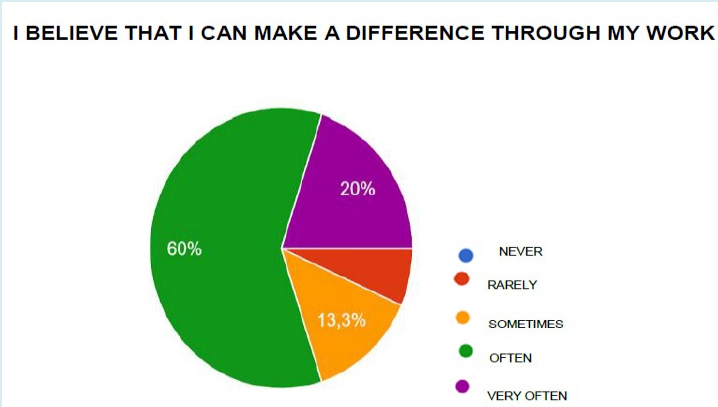

Figure 4: The graph represents the percentage of people interviewed who have experienced the feeling that they can make a difference in doing their job.

$50 \%$ of the interviewees never avoid certain activities or situations because he or she remembers scary experiences suffered by the people he or she helps, $21.7 \%$ rarely, $26.1 \%$ sometimes and $2.2 \%$ often. 
$50 \%$ is very often proud of what he or she could do in order to help others, $41.3 \%$ often.

$50 \%$ is never assailed by sudden involuntary frightening thoughts because of his or her work of helping, $21.7 \%$ rarely, $23.9 \%$ sometimes and $4.4 \%$ often.

As can be observed in figure 5, 13.6\% never feels blocked by the administrative and bureaucratic aspects of his or her work, 13.6 rarely, $31.8 \%$ sometimes, $20.5 \%$ often and $20.5 \%$ very often feels blocked by the bureaucracy of his or her work.

I FEEL BLOCKED BY THE ADMINISTRATIVE AND BUREAUCRATIC ASPECTS OF MY WORK

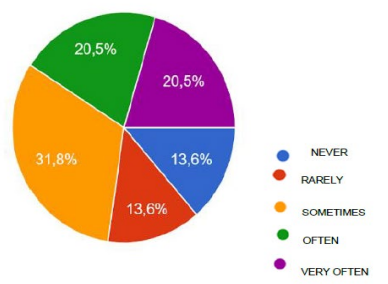

Figure 5: The graph represents the percentage of people interviewed who have experienced a feeling of blocking the bureaucratic aspects of the profession.

$11.1 \%$ very often thinks he or she is successful in his or her role of helping others, $53.3 \%$ often, $31.1 \%$ sometimes and $4.5 \%$ rarely.

$33.3 \%$ of the sample is never able to remember important aspects of his or her work with trauma victims, $28.9 \%$ rarely, $31.1 \%$ sometimes and $6.7 \%$ often.

$8.9 \%$ is rarely an overly caring person, $31.1 \%$ sometimes, $44.4 \%$ often, $13.3 \%$ very often and $2.3 \%$ is never an overly caring person.

I'M HAPPY FOR HAVING CHOSEN TO DO THIS WORK

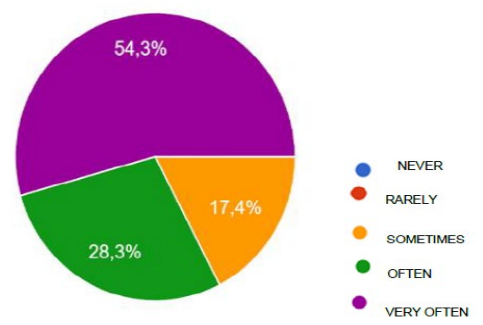

Figure 6: The graph represents the percentage of people interviewed who have experienced a feeling of happiness in choosing to do their job.
Figure 6 highlights how $54.3 \%$ of healthcare professionals interviewed very often is happy to have chosen to do his or her job, $28.3 \%$ often and $17-4 \%$ sometimes.

\section{Conclusion}

The results have shown that during the period of public health emergency the increase in the number and intensity of health care staff to support COVID-19 positive patients and indirectly their families, led them to experience problems with their work in terms of effectiveness and quality of life.

The experience of the pandemic has seen the health care staff come into direct contact with the experiences of other people and their own, both positive and negative, feeling compassion for the patients and helplessness in the face of death. In fact, $50 \%$ of respondents reported that they often felt concerned about more than one of the people they helped. $4.3 \%$ very often found it difficult to separate their private life from their role, with repercussions on their sleepwake cycle (19.6\%). 15.2\% felt as if he or she were on the brink or experiencing the trauma reported by the people he or she helped.

Finally, 25.6\% sometimes felt worn out because of his or her role in helping during the pandemic. The descriptive study highlights how psychologists, psychotherapists, pharmacists, doctors, nurses, medical technicians and neuropsychomotricists experienced a reduction in the perceived quality of professional life during the pandemic period.

\section{References}

1. Gross JJ, Thompson RA (2007) Emotion Regulation: Conceptual Foundations. In Gross JJ, (Ed.), Handbook of emotion regulation, The Guilford Press, pp: 3-24.

2. Gross JJ (2007) Handbook of emotion regulation. The Guilford Press, New York.

3. Izard CE (2010) The many meanings/aspects of emotion: Definitions, functions, activation, and regulation. Emotion Review 2(4): 363-370.

4. Linehan MM (1993) Cognitive-behavioral treatment of borderline personality disorder. Skills training manual for treating borderline personality disorder, The Guilford Press, New York.

5. Melnick SM, Hinshaw SP (2000) Emotion regulation and parenting in $\mathrm{AD} / \mathrm{HD}$ and comparison boys: linkages with social behaviors and peer preference. Journal of Abnormal Child Psychology 28(1): 73-86. 
6. Cole PM, Michel MK, Teti LO (1994) The development of emotion regulation and dysregulation: a clinical perspective. Monographs of the Society for Research in Child Development 59(2-3): 73-100.

7. Gross JJ, Munoz RF (1995) Emotion regulation and mental health. Clinical Psychology: Science and Practice 2(2): 151-164.

8. Hayes SC, Wilson KG, Gifford EV, Follette VM, Strosahl K (1996) Experimental avoidance and behavioral disorders: a functional dimensional approach to diagnosis and treatment. Journal of Consulting and Clinical Psychology 64(6): 1152-1168.

9. Sica C, Magni C, Ghisi $M$, Altoè $G$, Sighinolfi $C$, et al. (2008) An updated tool for measuring coping styles: the Coping Orientation to the Problems Experienced-New Italian Version (COPE-NVI). Cognitive And Behavioral Psychotherapy 14: 37-63.

10. Hayes SC, Strosahl KD, Wilson KG (1999) Acceptance and commitment therapy. An experiential approach to behavior change. The Guilford Press, New York.

11. Zhu N, Zhang D, Wang W, Li X, Yang B, et al. (2020) A novel coronavirus from patients with pneumonia in China, 2019. New England Journal of Medicine 382(8): 727-733.

12. Naicker S, Yang CW, Hwang SJ, Liu BC, Chen JH, et al. (2020) The novel coronavirus 2019 epidemic and kidneys. Kidney Int 97(5): 824-828.

13. Galati D, Fassio O, Viglino M (2004) Motivazioni ed emozioni dei medici e degli infermieri del pronto soccorso. Nuove Tendenze Psicologia 2: 392-412.

14. Huggard P, Stamm BH, Pearlman PA (2013) Physician stress: Compassion satisfaction, compassion fatigue and vicarious traumatization. In: Figley CR, Huggard P, (Eds.), First do no self-harm: Understanding and promoting physician stress resilience, Oxford University Press, USA.

15. Hundall Stamm B (2009) Professional Quality of Life Measure: Compassion, Satisfaction, and Fatigue Version 5 (ProQOL). 